International Archives of the Photogrammetry, Remote Sensing and Spatial Information Sciences, Volume XL-7/W1, 3rd ISPRS IWIDF 2013, 20 - 22 August 2013, Antu, Jilin Province, PR China

\title{
RESEARCHES ON THE LAND-USE CHANGE DETECTION OF MINE AREA BASED ON TM/ETM IMAGES
}

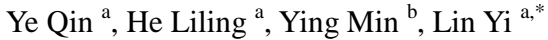 \\ a Research Center of Remote Sensing and Spatial Information Technology/College of Surveying and \\ Geo-Informatics,Tongji University, Shanghai 200092,China - (yeqin ; linyi ; 0410_heliling)@tongji.edu.cn \\ b 73011 Troops, Huzhou 313006, China - 11yingmin@ @ongji.edu.cn
}

KEY WORDS: Support Vector Machine, Change Detection, Dynamic Analysis, Mining Area, LUCC

\begin{abstract}
:
With the economic development and population growth, land use status is changing rapidly in Chinese urban. Since the remote sensing technology can analyze and detect the land use information quickly and accurately, it has been widely applied to obtain the land use/land cover change (LUCC) information today. The land surface destroy occurred in mineral resources exploration will result in a lot of environmental problems in coal mine areas. But there are few research in small and medium-sized cities and coal mine areas. So Peixian is used as the study area in the paper. The Landsat TM/ETM images spanning 3 years and thematic map are adopted to detect the land-use change of the area. In order to improve the classification results, we built an optimized classification model adapting classic SVM method, which was defined "a feature weighted SVM classifier using mixed kernel function”. Based on geostatistic and multi-scale statistical knowledge, we calculated the transformation matrix and dynamic index of land-use types, from which we conducted quantitative analysis and the driving force on the mine land-use change of Peixian. Then, we can achieve resource dynamic change detection of four years in Peixian area, analyze the effect of the surface land-use change due to mineral exploration and obtain the causes of land-use change.
\end{abstract}

\footnotetext{
* Corresponding author: Tel: +86-021-659-81867

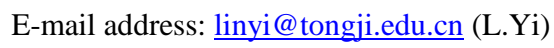




\section{INTRODUCTION}

Land use and land cover change (LUCC) is very important in the global change of population, resources and environment, and has been an important cause of global environment change since 1990s. At present, LUCC has become a frontier and hot spot in the international global change research. In recent years, the research of regional land use change has been deepened and widened intensely. Land use is changing rapidly in Chinese urban area during the last thirty years. There are many researches studying land-use change detection in some metropolitan and developed areas now. But there are few researches in small and medium-sized cities and coal mine areas. The land surface destroy occurred in mineral resources exploration will result in a lot of environmental problems. When mineral resources exploited, the mining land will severely collapse, accompanied by surface disturbance which makes the landscape pattern around the mine changing rapidly in a short time. On the one hand, the conventional mining causes the mining subsidence and a refuse heap arises on the ground; on the other hand, the infrastructure construction, village relocation caused by coal mining and transportation of materials need the construction land. All of these will decrease the vegetation area and increase the construction area, a lot of land subsidence will form mining-induced collapse water-logged zone, destroying the ecological environment in the mining area. In this paper, Peixian area is used as the study area. Remote sensing images are used for detecting the land use change. Based on change detection, the paper analyzes the law of land use change and the driving forces which cause the change, then provides a scientific basis for reasonable utilization of the land resources.

At present, there are many models used for the land use change researches, such as experienced statistical model, stochastic model, optimization model, dynamic model based on process and comprehensive model. There are also studies aiming to detect land use change by utilizing Remote Sensing (RS) images and spatial analysis technologies, both of which can analyze land use change qualitatively as well as quantitatively. Adams (1995) did monitoring analysis of dynamic change of various features using TM images of 1988 and 1991 in Amazon basin of Brazil; Hanan(1997) analyzed the trend of land cover change and the correlation of precipitation quantificationally in the Sahara area using archived RS data from 1920 to 1960. In Yanpei Qin(2001)'s study, two phases of Landsat TM data of 1988 and 1998 being used, the technical method of RS and GIS being adapted, the sand hill region between Zhengzhou city and Kaifeng city was investigated by dynamic monitoring and analytical research of LUCC. In order to analyze LUCC issues comprehensively, studies on land use change of mining area are of great significance to understanding land use change effect on the regional ecological system. Shiping $\operatorname{Li}(2008)$ used RS data to conduct dynamic monitoring of land use of a typical mining area in North-East China and obtained the basic law of land use change of mining area. Xin Fan (2012) selected the TM images of 1987,2000 and 2010 in Huainan mining area to analyze the situations of land use and the changes of land use structure.

In this paper, we choose the mining area in Peixian,Xuzhou as a study area; and discuss the land use change and its driving forces during recent 4 years. Since the traditional classification methods that applied in the researches above may not meet the accuracy of image classification and not be suitable for the study on the mining area, this paper adopts an improved support vector machine(SVM) model to classify land types of the mining area after analyzing existing methods of RS image classification. Then we study the gradual change and conversion of LUCC after images have been classified. 


\section{MATHEMATICAL FOUNDATIONS}

\subsection{The RS image classification based on improved}

\section{SVM}

In the detection of land use change, multi-temporal RS images of the same areas mainly serve three purpose:1)providing the ground feature distribution; 2)describing the change information; 3)analyzing the LUCC qualitatively and quantitatively. The common ways used in LUCC can be categorized into two types: direct comparison method and post-classification comparison method. We use the latter one here. The post-classification comparison method can not only give a change information of land-use types but also can describe the transition information. It is very effective for considering the cross change of many types. The classification accuracy will influence the extraction of image change information. Now, there are many classifiers; such as maximum likelihood classifier, decision tree classifier, neural network classifier, and Support Vector Machine(SVM) classifier. The maximum likelihood classifier is assumed that all the bands accord with normal distribution, but if the pixels in the cluster groups or training samples are distributed dispersedly, it will tend to overdo the classification. This is not suitable for many RS image classification.

SVM, as a new effective statistical learning method, has the superiority compared with traditional classifiers in RS image classification. SVM is built on the principle of structural risk minimization(SRM). It needs to find a optimal separating hyperplane by solving a quadratic programming problem. The core contents are: 1)choosing a suitable map; 2)mapping the sample points of input space to an high dimensional feature space; 3)making the corresponding sample points linear divided in the space. So we need to find the separating hyperplane with a maximum margin $\mathrm{w} \cdot \mathrm{x}+\mathrm{b}=0$, which can satisfy the decision function $f(x, \alpha)$ of SRM. For the problem of nonlinear separable samples, the low dimensional linear non-separability can be transformed to the high dimensional linear separability by using the nonlinear mapping function $\Phi(\mathrm{x})$. And the corresponding nonlinear classification function is:

$f(x)=\operatorname{sgn}\left(\sum_{i=1}^{l} \alpha_{i} y_{i}\left(\varphi(x) \cdot \varphi\left(x_{i}\right)\right)+b\right)=\operatorname{sgn}\left(\sum_{i=1}^{l} \alpha_{i}^{*} y_{i} K\left(x, x_{i}\right)+b^{*}\right)$

Where $b^{*}$ is a classified valve's value, which can be calculated by one support vector or taking mean from a pair of support vectors; and $K\left(x_{i}, x_{j}\right)=\varphi\left(x_{i}\right) \cdot \varphi\left(x_{j}\right)$ is the kernel function.

The selection of kernel function affects the fitting ability and prediction accuracy of the SVM model. Smits G.F. and Jordan E.M. proposed a mixed kernel function of global and local kernels $K_{\text {mix }}$. In order to improve the classification accuracy, we build an optimized classification model on the basis of the original standard SVM algorithm model, which is defined "a feature weighted SVM classifier using mixed kernel function".

This model can provide better classification performance, while avoiding being dominated by weak correlation characteristics.

$$
K_{\text {mi x }}=\lambda K_{\text {po } 1 \mathrm{t}}(1-\lambda) K_{\text {r b }}
$$

Let $\lambda \in(0,1)$ be the number of kernel parameter, which generally is between 0.55 and 0.99 . Then for the set of selected number $\lambda$, we know that the performance of mixed kernel function will be better if there is a higher parameter $\lambda$.

Obtaining the weight vector $\mathrm{w}$ is the key to the weighted feature method which is applied in the SVM classification model. Feature weight calculation is usually based on a measure method which measures the importance of the feature. Many common methods have been used to measure the feature weight such as information gain, information gain ratio and the gini index. This paper adopts information gain ratio to construct the feature weight vector $\omega$ and proposes a feature weight kernel function:

$$
K_{P}\left(x_{i}, x_{j}\right)=K\left(x_{i}^{T} P, x_{j}^{T} P\right)
$$


Where $P=\left[\begin{array}{llll}w_{1} & & & \\ & w_{2} & & \\ & & \mathrm{O} & \\ & & & w_{\mathrm{n}}\end{array}\right]$ is a matrix of

linear transformation of order $\mathrm{n}$, also called feature weight matrix, and $\mathrm{n}$ is the dimensions of input space.

We use this improved SVM classification method to classify the land use change and extract the land use types, in order to analyze the change of land use and the driving force.

\subsection{The analysis of land-use change and driving}

\section{force}

The transformation matrix of land use describes the conversion between the area of land types. ${ }^{\text {I21 }}$ It can be used for analyzing the land-use change during some periods. And the results are reflected in a two-dimensional form. This paper adopts dynamic index which can describe the rate of land-use change to measure the dynamic degree of land-use types in the study area. The index considers the transfer of land-use types, and its focuses on the process of change rather than the change results. The calculation formula is as follow:

$$
L C=\left[\frac{\sum_{\mathrm{i}=1}^{\mathrm{n}} \Delta L U_{\mathrm{ij}}}{\sum_{\mathrm{i}=1}^{\mathrm{n}} L U_{\mathrm{i}}}\right] \times 100 \%
$$

Where $L U_{\mathrm{i}}$ is the area of land use type-i at the beginning of study period, and $\Delta L U_{\mathrm{ij}}$ means the area that land use type-i turns to land use type- $(j \neq i, j=1$, $2 \ldots \mathrm{n})$ during the period of this study (2005-2009). The dynamic degree of land use can be calculated according to the land use transformation matrix.

The driving force is the main factors that causes the change of land use patterns in geographical environment and community economy. As for mining area, there are many factors affecting the land use change. The change of water area is mainly affected by mining-induced collapse water-logged zone and policy planning; the change of vegetation area is mainly affected by the land consolidation; the change of construction area is mainly affected by the mining area construction, village's move and the population. This paper analyzes the factors of the change of land types based on the transformation matrix of land use, dynamic index and the investigation data.

\section{METHOD AND PROCEDURE}

The detailed flow chart is shown in figure1. First, RS images' rectification and registration are done in preprocessing. Then the images are classified based on the improved SVM classification model in order to extract the main land-use types. On this basis, we calculate the transformation matrix and dynamic index of land-use types, from which we conduct a quantitatively analysis of the driving force on the mine land-use change. Then, we can achieve dynamic land-use change detection.

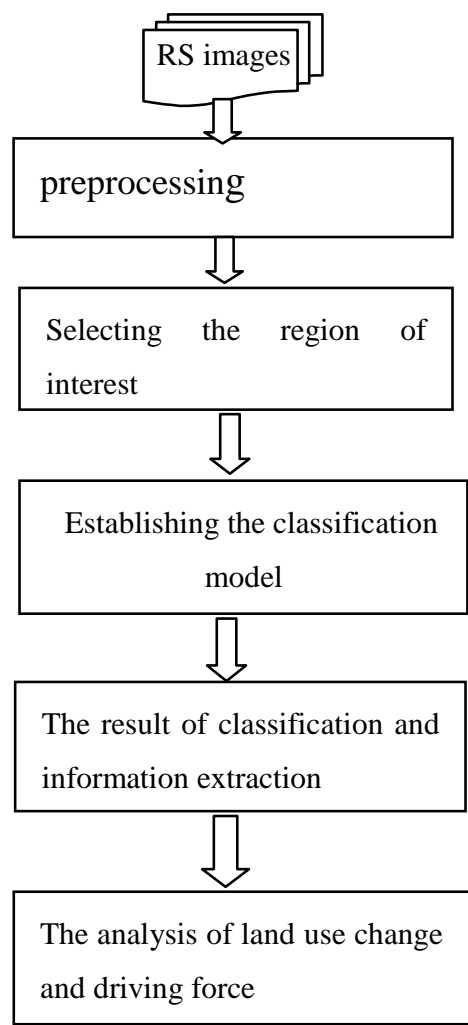

Figure 1. The flow chart of the land use change detection 
International Archives of the Photogrammetry, Remote Sensing and Spatial Information Sciences, Volume XL-7/W1, 3rd ISPRS IWIDF 2013, 20 - 22 August 2013, Antu, Jilin Province, PR China

Preprocessing: The TM/ETM data are used in the detection of land-use change, however, the datasets inevitably contain disturbances, such as geometric distortion. Those disturbances degrade the data quality. Therefore, we need to do some image preprocessing(geometric rectification, registration, and clipping).

Selecting the region of interest: First, the images were processed using principal component analysis (PCA). Then, considering the land use materials we obtain and the resolution of RS images, the main ground objects are divided into three categories in this research: signed construction, water and vegetation. Among them, the vegetation consists of farmland and green land; construction includes mining area land, habitation and traffic land; the water includes natural water, ponds and mining-induced collapse waterlogged zone.

Establishing the classification model: First, build the feature weighted vector $\omega$ and the diagonal matrix of linear transformation $P$. The feature importance is weighted by a linear transformation of multidimensional feature space. Second, combining the mixed kernel function and feature weighted method, the images can be classified by means of the optimal separating hyperplane.

Extraction and analysis: The vector layers of water, vegetation and construction areas are extracted to calculate the transformation matrix of land use. By integrating correlative date about the study area during the period of 2005 2009, this paper analyzes the land use change and the driving forces that cause the change.

\section{EXPERIMENTAL RESULTS AND}

\section{DISCUSSION}

\subsection{Research area}

Peixian is the study area in this paper(figure 2). It located in Xuzhou, Northwest Jiangsu province, is an important part of China's largest coal industrial base. The center of the area is at $34^{\circ} 43^{\prime}$ north latitude and $116^{\circ} 55^{\prime}$ east longitude. Peixian has rich coal resources. Frequent mining makes the surface change obviously. In Peixian, there are many mining areas such as Xuzhuang coal mine,Kongzhuang coal mine, Yaoqiao coal mine,Longdong coal mine and so on. Xuzhuang coal mine, which is located in the west of Weishan lake, is the earliest exploitation in Datun mining area. The total industrial reserve is 370 millions tons and the raw coal's production capacity is 1500 thousands tons now.

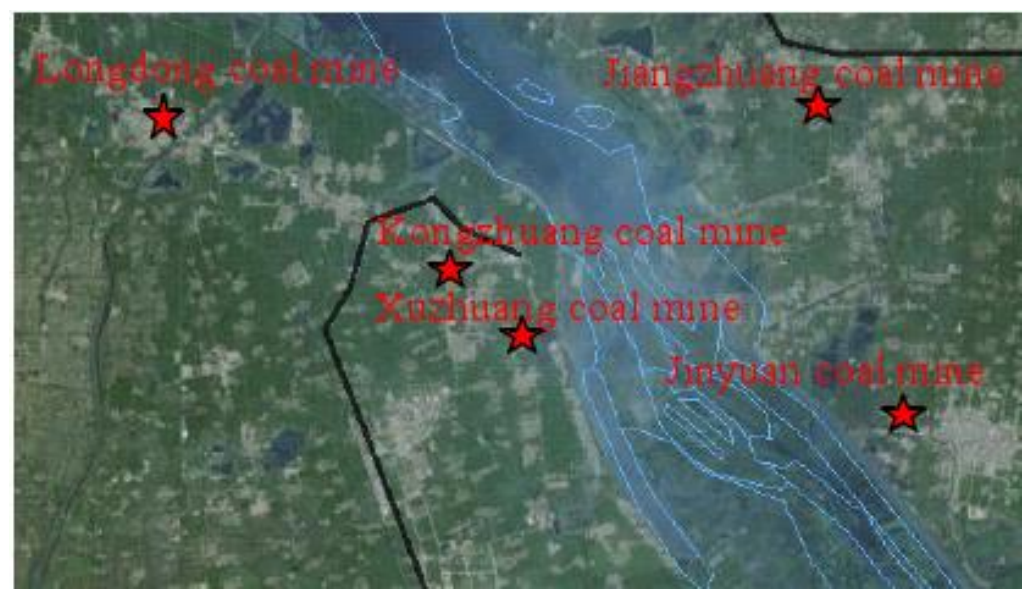

Figure 2. The study area of Peixian in Xuzhou 
International Archives of the Photogrammetry, Remote Sensing and Spatial Information Sciences, Volume XL-7/W1, 3rd ISPRS IWIDF 2013, 20 - 22 August 2013, Antu, Jilin Province, PR China

\subsection{Experimental Data}

We choose TM/ETM multispectral images of

Xuzhou-Peixian Area, in which the square measure of

\begin{tabular}{|c|c|c|c|c|c|}
\hline $\begin{array}{c}\text { Landsat } \\
\text { Satellite }\end{array}$ & Sensor & Band & Date(Y/M/D) & Number & Pixel Res \\
\hline Landset 7 & ETM+ multi- & $1,2,3,4,5,7$ & $2005 / 08 / 11$ & $122 / 36$ & 30 \\
spectral & ETM+ multi- & $1,2,3,4,5,7$ & $2007 / 09 / 02$ & $122 / 36$ & 30 \\
\hline Landset 7 & spectral & & & & meter \\
\hline Landset 5 & TM multi- spectral & $1,2,3,4,5,7$ & $2009 / 08 / 30$ & $122 / 36$ & 30 \\
& & & & & meter \\
\hline
\end{tabular}

Table 1. Main characteristics for the selection of RS data source in study area

Fig.3 is the original TM/ETM images of 2005,2007,2009 at the band 543-RGB.
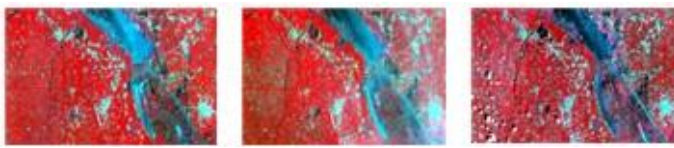

Fig.3. The TM/ETM images of 2005,2007,2009 at the band 543-RGB

Besides, we obtain some supplementary materials about Peixian, such as the table of land-use structural adjustment, the statistics of land-use change and the overall planning of land-use.

\subsection{Classification}

We build a feature weighted SVM classifier using mixed kernel function (2.1) based on the libsvm_mat3.12 toolkit in the Matlab. Then the the experimental area is $877 \mathrm{~km}^{2}$. The details of these acquired images are presented in table1. 
International Archives of the Photogrammetry, Remote Sensing and Spatial Information Sciences, Volume XL-7/W1, 3rd ISPRS IWIDF 2013, 20 - 22 August 2013, Antu, Jilin Province, PR China

probability of classified error is. According to the definition of J-M distance, if the degrees are greater than 1.9, it indicates that two kinds of objects have good separability. The table 2 shows that the degrees are concentrated in 1.9.

By analyzing the accuracy of different classification methods, we use the improved method of SVM classifier to classify the RS images (2.1), and obtain

(a) 2005

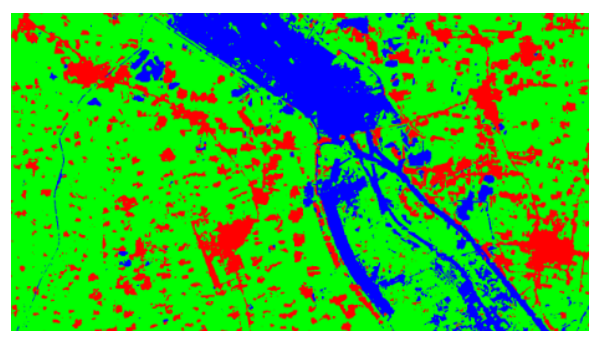

(c) 2009 the supervised classification result. we choose the post-classification comparison method to detected the land use and cover change. The incorrect of classification was modified by human-computer interaction and some fragmentary data was filtered out after post classification. Fig. 4 shows the result maps of land-use classification from 2005 to 2009. (b) 2007

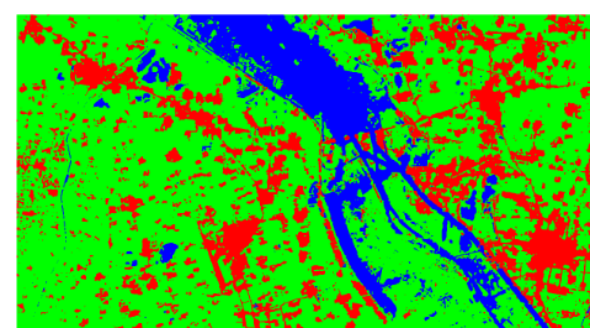

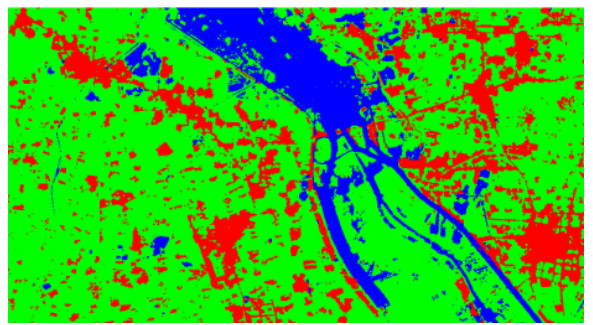

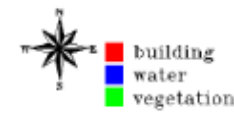

Fig.4. Land use maps of the study area in Peixian

On the basis of land-use classification result from land-use types quantitatively. 2005 to 2009 , we can obtain fig.5, it shows the area of

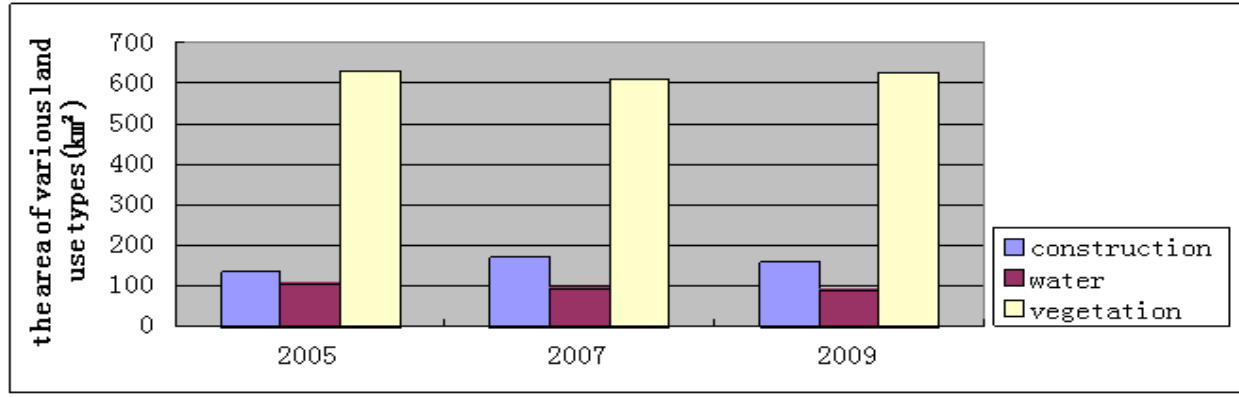

Fig.5. The area of land use types from 2005 to 2009

The overall accuracy and kappa coefficient are calculated based on an error matrix for each classified map. Through the calculation, the overall accuracy for each classified map is over $85 \%$ which attains the accuracy requirements. Making reference to the map data in the study area, we choose 150 sample points as the Ground Truth ROIs and calculate that the kappa coefficients of three land use maps are about 0.90 respectively. When Kappa $\geq 0.75$, the result has a reasonable level of accuracy and is sufficient for land-use analysis and change detection.

\section{the extraction of object information:}

1) land-use change analysis in experimental area

We used the layer D-value method to analyze the land-use change information in the study area. By using the results of classified maps from 2005 to 2009 , 
International Archives of the Photogrammetry, Remote Sensing and Spatial Information Sciences, Volume XL-7/W1, 3rd ISPRS IWIDF 2013, 20 - 22 August 2013, Antu, Jilin Province, PR China

the changes in study area can be identified in two different periods: 2005 to 2007 and 2007 to 2009 . Through the choice of each sample extracted from classified maps, we can definitely find the change and non-change areas. Here the water is used as an example, fig.6 shows the vector layer of water area from 2005 to 2009 . Then D-value operation is done in any of two phases, the change information of water area is presented in fig.7.

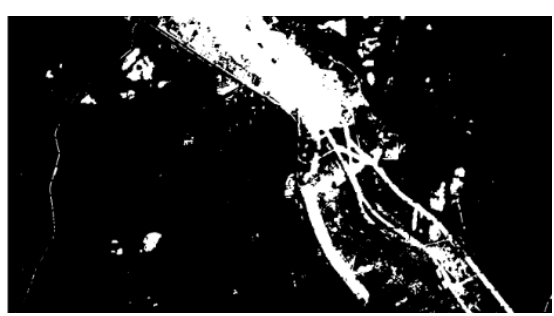

a)the vector extraction of water area of 2005

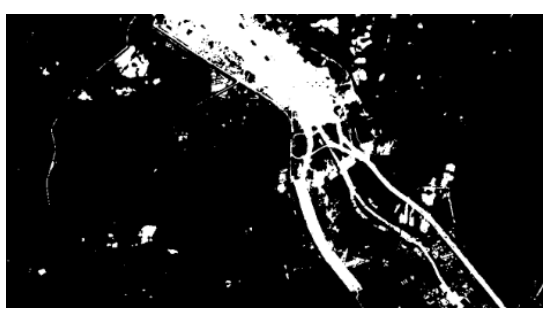

c)the vector extraction of water area of 2009

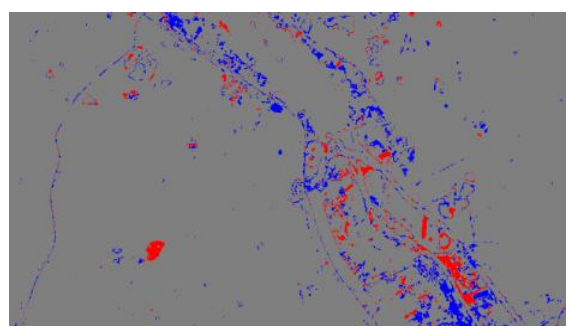

a) the change detection of water area from 2005 to 2007
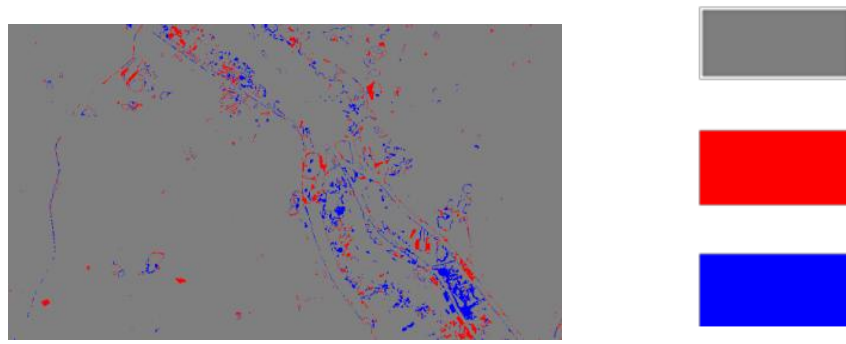

non-change

other-water

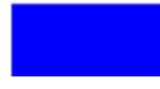

water-other

b) the change detection of water area from 2007 to 2009

Fig.7. the change detection of water area from 2005 to 2009

2 )analysis of land-use transformation matrix

In order to analyze the transfer of land-use types, we do the statistics and matrix operations to count the variable quantity of land-use in two periods. Table 3 and 4 show the land-use transformation matrix and percent conversion of different types.

\begin{tabular}{|l|l|l|}
\hline the land-use transformation & 2005 & \\
\hline
\end{tabular}


International Archives of the Photogrammetry, Remote Sensing and Spatial Information Sciences, Volume XL-7/W1, 3rd ISPRS IWIDF 2013, 20 - 22 August 2013, Antu, Jilin Province, PR China

\begin{tabular}{|c|c|c|c|c|c|}
\hline \multicolumn{2}{|c|}{ matrix } & construction & water & vegetation & Total 2007 \\
\hline \multirow{4}{*}{2007} & construction & 119.39 & 1.78 & 50.80 & 171.97 \\
\cline { 2 - 6 } & $\mathrm{P} \%$ & 86.645 & 1.650 & 8.050 & \\
\cline { 2 - 6 } & water & 0.88 & 83.68 & 11.65 & 96.2 \\
\cline { 2 - 6 } & $\mathrm{P} \%$ & 0.638 & 77.487 & 1.846 & \\
\cline { 2 - 6 } & vegetation & 17.52 & 22.53 & 568.57 & 608.62 \\
\cline { 2 - 6 } & $\mathrm{P} \%$ & 12.717 & 20.863 & 90.104 & \\
\hline \multicolumn{2}{|c|}{ Total 2005 } & 137.79 & 107.97 & 631.01 & 877 \\
\hline
\end{tabular}

Table3. The land-use transformation matrix of study area from 2005 to 2007

\begin{tabular}{|c|c|c|c|c|c|}
\hline \multirow{2}{*}{$\begin{array}{c}\text { the land-use transformation } \\
\text { matrix }\end{array}$} & \multicolumn{3}{|c|}{2007} & \multirow{2}{*}{ Total 2009 } \\
\cline { 2 - 5 } & construction & water & vegetation & 157.91 \\
\hline \multirow{3}{*}{2009} & construction & 125.83 & 0.80 & 31.28 & \\
\cline { 2 - 5 } & $\mathrm{P} \%$ & 73.145 & 0.827 & 5.146 & \\
\cline { 2 - 5 } & water & 1.29 & 81.68 & 10.67 & 93.64 \\
\cline { 2 - 5 } & $\mathrm{P} \%$ & 0.751 & 84.917 & 1.755 & \\
\cline { 2 - 6 } & vegetation & 44.91 & 13.71 & 566.01 & 624.63 \\
\cline { 2 - 5 } & $\mathrm{P} \%$ & 26.105 & 14.256 & 93.100 & \\
\hline \multicolumn{2}{|c|}{ Total 2007} & 172.02 & 96.19 & 607.96 & 877 \\
\hline
\end{tabular}

Table 4. The land-use transformation matrix of study area from 2007 to 2009

According to the table 3, table 4 and equation (4), the land-use dynamic index was $11.99 \%$ in the first periodfrom 2005 to 2007 , while $11.70 \%$ in the second period from 2007 to 2009 .

\subsection{The analysis of experimental results}

\subsubsection{Analysis of land-use change}

After comprehensive analysis of table 3 and table 4, vegetation area accounts for the largest proportion. It accords with the characteristic of rich agricultural and forestry resources in Peixian. Furthermore, we can discuss the land-use changes of mine area in Peixian for the past 4 years.

1) From 2005 to 2009 , the area of construction and vegetation changed alternately. For the first period from 2005 to 2007, the construction area increased 34 $\mathrm{km}^{2}$ and the vegetation decreased $23 \mathrm{~km}^{2}$; For the second period from 2007 to 2009, the construction area decreased $14 \mathrm{~km}^{2}$ and the vegetation increased 16 $\mathrm{km}^{2}$. This kind of land-use change was mainly caused by the result of reclaim of mining area development and land reclaim. Economic development and national policies made the construction land increasing. But in mineral exploration, the construction area collapsed. It changed into unused land, while the unused land changed into green space after the backfill.

2) The water area reduced and changed into vegetation area during the study period. The reasons can be concluded to three aspects: (1)the local government land-use planning; (2)the long-term accumulation of silt; (3)classification error on the water and land boundary.

\subsubsection{Analysis of driving force}

In general, all the restricting factors can be concluded into two aspects of the nature and social economy. The study area is rich in coal resources, so the long-term coal mining, land reclamation and population policy affected the change of land-use types. 
International Archives of the Photogrammetry, Remote Sensing and Spatial Information Sciences, Volume XL-7/W1, 3rd ISPRS IWIDF 2013, 20 - 22 August 2013, Antu, Jilin Province, PR China

1) Population growth. At the end of 2005, the total population of Peixian has reached 163066. The increase of population will inevitably lead to the increase of the demand for housing, transportation and public facilities, so the construction area has a trend of land expansion.

2) Economic development. With the development of economy, the demand of energy source accelerates the extraction rate of coal mines which will cause land use pattern change. There are 50 mining companies in Peixian in 2007, which increased more than 50\% compared with that in 2005. It illustrates that the development of mining area will substantially occupy the land area, leading to the increase of construction area.

3) Policy promotion. Land use planning will effect land use pattern in some degree. The scheme of land use planning of Peixian from 2005 to 2020 shows that the water area will be down-regulated. During the planning period, the regional construction will lead to a 64.85 hectares reduction of the water area, and the land development will lead to a 29.02 hectares reduction. The results show that the water area was in decline from 2005 to 2009.

\section{CONCLUSION}

In this paper, the TM/ETM images of 2005,2007 and 2009 are adopted to classify the study area, extract the land types and detect the land-use change in Peixian area.

Based on standard SVM algorithm, we improve the SVM classification model by using the feature weighted and mixed kernel function. Compared with other classification model, this classifier has a better classification accuracy. We prove that the improved classification method of SVM can satisfy the classification in mining area.

By analyzing the transformation matrix of land use and the change maps of land use types during the study period, we draw a conclusion that it is feasible to use the TM/ETM images to do the research of land use change in the mining area. Then the results of the study can provide the decision basis for development of the mining area.

\section{ACKNOWLEDGEMENTS}

This research is supported by the research project of Ministry of Land and Resources (Project ID: 201211011-03). The authors acknowledge the support of Shanghai Committee of Science and Technology.

\section{REFERENCES}

[1] WU Wenbo, WU Yun, JI Cuicui, YAO Jing. Land Use Change in Fuxin Mining Area [J]. Journal of Anhui Agricultural Sciences,2009,30:14848-14851.

[2] HU Zhaoling, DU Peijun, ZHAO Xin. Land Use Changes in Xuzhou Coal Mining Area [J]. ACTA GEOGRAPHICA SINICA,2007,62(11):1204-1214.

[3] LU Chun-yang, QI Lei-gang, SANG Chao-jie. Analysis on Mathematic Model of Land- use Changes [J].RESOURCE DEVELOPMENT \& MARKET,2007,23(1):25-27.DOI:10.3969/j.issn.1005-8141.20 07.01.008.

[4] YAN jie, WEI Hai-yan, XUE Liang, LI Fu-li. A STUDY OF THE LAND USE CHANGE AND THE DRIVINGFORCE IN XI'AN CITY BASED ON INDEX ANALYSISHUO [J]. REMOTE SENSING FOR LAND \& RESOURCES,2009,(2):49-53.

[5] LI Shiping, WU Wenbo, LIU Zhenggang. Study on Land Use Change in Mining Area Based on RS Images[J].MINE SURVEYING, 2008,(5):11-13. DOI: 10.3969/j.issn.1001-358X.2008.05.003.

[6] YUE Qiu-li, YAN Shi-qing, LUO Li, CHI Jian. Land use change based on RS and statistic analysis [J]. JOURNAL OF HENAN POLYTECHNIC UNIVERSITY(NATURAL SCIENCE), 2010, 29(2): 201- 205. DOI: 10.3969 /j.issn.1673-9787.2010.02.013.

[7] DU Jun, YANG Qing-hua. An Analysis of Regional Ecological Risk Based on Land Use Change and Spatial Statistics:A Case Study in Wuhan, Hubei Province [J]. REMOTE SENSING FOR LAND \& RESOURCES, 2010,(2):102-106.

[8] QIU Bingwen, CHEN Chongcheng. Land Use Change Simulation Model Based on MCDM and CA and Its Application [J]. ACTA GEOGRAPHICA 
International Archives of the Photogrammetry, Remote Sensing and Spatial Information Sciences, Volume XL-7/W1, 3rd ISPRS IWIDF 2013, 20 - 22 August 2013, Antu, Jilin Province, PR China

SINICA,2008,63(2):165-174.

[9] LI Hong-fen, HU Guang-dao, LI Jiang-feng. Grain Analysis of Land Use Spatial Pattern Based on Geo-Statistic Method [J]. GEOGRAPHY AND GEO-INFORMATION SCIENCE,2008,24(5):6-10.

[10] GUO Cheng-xuan, XU Song-jun, WU Xi-bo. SPATIO-TEMPORAL VARIABILITY OF LAND USE CHANGE DRIVING FORCES IN FOSHAN CITY BASED ON GEOSTATISTICS[J]. ECONOMIC GEOGRAPHY, 2009,29(9):1524-1529.

[11] SU Hai-min, HE Ai-xia. Analysis of Land Use Based on RS and Geostatistics in Fuzhou City [J]. JOURNAL OF NATURAL RESOURCES, 2010, 25 (1):91-99.

[12] Kembhavi A, Siddiquie B, Miezianko R, McCloskey S, Davis L S. Incremental multiple kernel learning for object recognition. In: Proceedings of the International Conference on Computer Vision. Washington D.C., USA: IEEE, 2009, 1-8.

[13] Allan Aasbjerg Nielsen, Morton John Canty. Kernel principal component analysis for change detection.In:SPIE Europe Remote Sensing Conference on Geoinformatics,Sep.2008,vol.7109. 